\title{
Mass transfer during osmotic dehydration of quince using different osmosis solutions
}

\section{Ana Leahu ${ }^{1}$, Cristina Ghinea ${ }^{1}$, Sorina Ropciuc ${ }^{1}$}

\author{
Stefan cel Mare University of Suceava, Romania
}

Keywords:

Cydonia oblonga

Quince

Colour

Polyphenols

Ascorbic acid

\section{Article history:}

Received 21.09.2020

Received in revised

form 16.01.2020

Accepted 25.03.2021

\section{Corresponding}

author:

Ana Leahu

E-mail:

analeahu@fia.usv.ro

DOI: $10.24263 / 2304-$ 974X-2021-10-1-9

\section{Abstract}

Introduction. Fructose and sucrose osmotic solutions, were tested in order to evaluate their effects on the characteristics of the osmosed quince. The effect of slice thickness, solution concentration and immersion time on the color and chemical characteristics of dehydrated quince (Cydonia oblonga) were studied.

Materials and methods. Weight reduction (WR), CIE color parameters, total phenolic (TPC) and ascorbic acid (AA) content were investigated using fructose and sucrose osmotic solutions for 3 hours immersion time. The content of the total polyphenols (TPC) was determined by the Folin-Ciocalteu reagent at $765 \mathrm{~nm}$ using spectrophotometer. Ascorbic acid (AA) content was separated, identified and dosed in a HPLC SHMADZU system coupled with UV-VIS detector (DAD).

Results and discussion. Weight reduction (WR, \%) of osmosed quince showed significant differences depending on the type and concentration of the osmotic agent and process time. Significantly higher moisture loss of fructose (monosaccharides) as an osmotic agent is a considerable advantage compared to sucrose (disaccharide). The higher values of WR were obtained when quince samples were dehydrated with fructose solution of $80 \%$ concentration. It was observed that after 180 min of osmotic dehydration with fructose solution $40 \%$, thinner slices $(10 \mathrm{~mm}$ ) have a higher WR value compared to thicker slices $(20 \mathrm{~mm})$. The total polyphenols content increased during the osmotic dehydration treatments with $80 \%$ osmotic solution. The ascorbic acid content increased during the treatments with fructose solution from $18.66 \mathrm{mg} / 100$ $\mathrm{g}$ (in fresh quince samples) to $30.9 \mathrm{mg} / 100 \mathrm{~g}$ (in quince samples after osmotic dehydration with fructose solution $80 \%$ ). The samples treated with $80 \%$ fructose had a lower $\mathrm{L}^{*}$ coordinate, showing an enzymatic browning. The value of $\mathrm{a}^{*}$ was minimal in the case of samples treated with $80 \%$ fructose, indicating that the hydrated quince showed a darker color compared to the fresh samples.

Conclusions.Osmotic dehydration for quince with the two osmotic solutions only slightly affected the compositional properties, such as total polyphenols and ascorbic acid content, and weight gain of osmotically dehydrated quince. 


\section{- Food Technology -}

\section{Introduction}

By air drying the fruits biological substances mainly vitamins, provitamins, polyphenols and other bioactive compounds sensitive to heat, light and oxygen are degraded (Zielinska et al., 2017). In order to reduce nutrient losses, pretreatment is often applied to improve the quality of dry products (Turkiewicz et al., 2020). Osmotic dehydration leads to prolongation of the shelf life, small loss of colour in apple samples osmosed with glucose or sucrose solutions $30 \%, 45 \%(\mathrm{w} / \mathrm{w})$ at different times, and in glucose osmosed samples a greater texture hardening rate was observed (Mandala et al, 2005).This process consumes less energy than the air drying or vacuum drying process, osmotic dehydration of apple cubes at room temperature acts as a pre-treatment with a beneficial effect on the firmness of the rehydrated samples that had been air-dried at $50^{\circ} \mathrm{C}$ (Prothon et al., 2001).

Osmotic dehydration (OD) is the process in which pieces of fruit or vegetables are immersed for different periods of time in a hypertonic solution, so that some of the water and natural sugar in the fruit are replaced with sugar from the syrup (Fernandes et al., 2009).The cellular structure of food acts as a semi-permeable membrane, which is not completely selective and which results in two counter-currents of mass transfer: the diffusion of water from food into solution and the diffusion of osmotic solution into fruit (Yadav et al., 2014). Osmotic dehydration with different osmosis solutions is used to preserve the fruit, because the enzymatic browning (initiated by the enzyme polyphenol oxidase) is reduced, the retention of volatile substances is increased, the color is saved and the sweet taste is preserved (McEvily et al., 1992). The selection of a particular osmotic agent depends on its cost, its molecular weight, and the sensory characteristics of the product to be dehydrated (Ahmed et al., 2016). The most common osmotic agents are (Ahmed et al., 2016): sucrose, corn syrup solution, sodium chloride, maltose, honey, glucose, fructose, lactose, glycerol and ethanol. In general, osmotic dehydration is considered as a pretreatment used in the conventional drying of many agricultural products (da Silva et al., 2013).

Quinces (Cydonia oblonga Miller), are a species belonging to the Rosaceae family and represents one of the most important sources of vitamins, calcareous salts, bioactive components such as flavonoids and dietary fiber, compounds with health-promoting properties (Dehghannya et al., 2018). Traditional Quince fruits uses are in the preparation of jams, marmalades, purees and jellies, but can be added in ice cream, yogurt or confectionery products (Turkiewicz et al., 2019).

Although, quince fruits are less suitable for direct consumption due to their astringent and strong flesh, the most important advantage of quince over other fruits is its high content of vitamin C. Thus, for example, in some varieties at the ripening stage of consumption, the vitamin C content was over $70 \mathrm{mg} / 100 \mathrm{~g}$ fresh weight (FW) (Rop et al., 2011).

Quince is rich in polysaccharides, which is $11 \%$ (dry weight) in the flesh (Qin et al., 2020), pectin (0.53 to $1.83 \mathrm{~g}$ pectin/ $100 \mathrm{~g}$ fresh quince) (Borazan et al., 2017), contain organic acids such as oxalic, citric, ascorbic, malic, quinic, shikimic, and fumaric acid (Silva et al., 2004) and phenolic compounds (16), which have health promotion roles and medicinal properties (Wojdyło et al., 2014).

Although, osmotic dehydration of quince is little studied, there are some papers available in the literature. For example, the effects of pretreatment on the osmotic dehydration of cubic pieces of quince fruit with sucrose osmotic solution (control, 10, 30, 50, and 70\% (w/w)) using intermittent microwave (IM) - dry hot air (HA) at a low temperature $\left(40{ }^{\circ} \mathrm{C}\right)$ were studied by Dehghannyaet et al. (2018). Thus, the increase in the concentration of the osmotic solution, the power and the pulse ratio led to significant decreases in contraction (Dehghannyaet et al., 2018). Recently, Turkiewicz et al. (2020) studied the effect of osmotic 
dehydration (DO) using fruit concentrates (apple, pear, pineapple, sour cherry, blackcurrant and hot pepper), as well as the antioxidant, antidiabetic and anticholinergic activity of dried Japanese quince before and after osmotic dehydration. After the completion of osmotic dehydration (in water baths at $45^{\circ} \mathrm{C}$ for $1.5 \mathrm{~h}$ ), Japanese quince fruits had an increased sugar content (up to 20 times more) and a significant reduction in organic acid content (even a 77\% reduction compared to non-OD fruits) (Turkiewicz et al., 2020)).

Therefore, the purpose of this article is to present the effect of osmotic dehydration pretreatment (fructose and sucrose 40,60 and 80\%) on the mass transfer color and chemical characteristics of quince fruits.

\section{Materials and methods}

\section{Materials}

Fresh Quinces (Cydonia oblonga Miller), were purchased from a local producerin Falticeni (Romania). For each experiment, the healthy fruits were carefully sorted and washed, cleaned by hand, and after removing the seeds were cut into $2 \mathrm{~cm}$ thick slice. All chemicals used for total phenolic content analysis, Folin's reagent and gallic acid, acid ascorbic content, were procured from Sigma Aldrich, Germany. Deionizer water was used.

\section{Osmotic pre-treatment}

In this report, the influence of fructose and sucrose solutions concentration and immersion time on mass transfer during osmotic dehydration was studied. Osmotic dehydration was performed at room temperature and three concentrations of fructose and sucrose solution $(40 \%, 60 \%$ and $80 \%)$ were used. Osmotic solutions were prepared by blending with distilled water on a weight-to-weight basis. The high concentration of osmotic solution was based on a comparative study in the literature (İspir et al., 2018). A ratio of 2:1 (200 ml osmotic solution: $100 \mathrm{~g}$ quince) was chosen to monitor changes in hypertonic solution concentration.

The fruits were placed in glasses and after the addition of the osmosis agent it was stirred with an orbital stirrer. The mass transfer between the sample and the fructose solution during osmotic dehydration was measured within 30, 60, 90, 120, 150 and $180 \mathrm{~min}$, the two dimensions of the cubes Quince and showed a different behavior during osmotic dehydration. The samples were removed from the osmotic solution then wiped gently with filter paper to remove adherent water and then weighed.

Each treatment was performed three times and each time with other fruits. Weight reduction (WR) is used to characterize osmotic dehydration, and was calculated according to the following equation (Leahu et al., 2020):

$$
\mathrm{WR} \%=\frac{W_{i}-W_{t}}{W_{i}} * 100
$$

where $W_{\mathrm{i}}$ is the initial weight of sample cubes $(\mathrm{g})$ and $W_{t}$ the weight of sample cubes after osmotic dehydration for at each sampling times $t(\mathrm{~g})$.

\section{Water activity}

Water activity $\left(\mathrm{a}_{\mathrm{w}}\right)$ was measured using a water activity meter (AQUALAB). 


\section{- Food Technology -}

\section{Total phenolic content (TPC)}

The degree of the methanolic extract of fruits was expressed as equivalent gallic acid (GA) (mg of gallic acid $100 \mathrm{~g}^{-1} \mathrm{fw}$ fresh weight) using a standard curve prepared at different concentrations of GA, and were assayed using the Folin-Ciocalteau reagent (Stankov et al., 2020). $1 \mathrm{ml}$ of freshly prepared Folin-Ciocalteau's reagent $(1: 10, \mathrm{v} / \mathrm{v}$, with water) and $0.8 \mathrm{ml}$ sodium carbonate $(7.5 \%)$ were added in $0.2 \mathrm{ml}$ of aqueous extract to quince fruit sample. Then, the mixture was incubated at room temperature for 2 hours, and spectrophotometric absorbance was measured at $765 \mathrm{~nm}$ using a spectrophotometer T70 UV-VIS PG Instruments Ltd.

\section{Determination of the ascorbic acid}

The ascorbic acid (AA - expressed in mg/100 g FW of fruits) content, was separated, identified and dosed in a HPLC SHMADZU system coupled with UV-VIS detector (DAD),

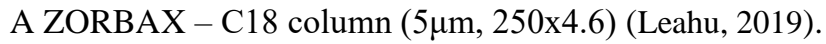

\section{Colour measurement}

Colour was measured on the surface of the fruit in terms of ' $L$ ' (lightness), ' $a$ ' ( $+\mathrm{a}$ is red, -a is green) and ' $b$ ' (+b is yellow, $-\mathrm{b}$ is blue) values (Leahu et al., 2018). Variations in the values of $L^{*}, a^{*}$ and $b^{*}$ were measured due to different osmotic pretreatments using a Minolta Chroma counter (Model CR 400/410) (Leahu et al., 2018).

\section{Moisture content}

The content of water from the quince fruits was determined after drying to constant weight at the standard temperature of $105 \pm 2{ }^{\circ} \mathrm{C}$ (Rop et al., 2011). The samples used in the research constituted $5 \mathrm{~g}$ of the sample that has been dried in an oven at $103^{\circ} \mathrm{Cat}$ atmospheric pressure until constant weight was obtained. Moisture (g water/100 g of sample) $\%$ was calculated by using the following equation:

$$
\mathrm{M} \%=\frac{M_{i}-M_{s}}{M_{i}} * 100
$$

where $M_{\mathrm{i}}$ is the initial weight of sample cubes $(\mathrm{g})$ and $M_{s}$ is the mass of sample's dry solids (g). The sample mass was determined using a digital balance.

\section{Statistical analysis}

Data were expressed as means \pm standard deviations for triplicate determination. Statistical significance of differences between the individual treatments was evaluated by using one-way ANOVA (Minitab 17 software). The null hypothesis was "All means are equal", while the alternative hypothesis was "At least one mean is different". The significance level considered was $\alpha=0.05$. 


\section{Results and discussion}

\section{Physico-chemical parameters of fresh and osmotic dehydrated quince}

Osmotic dehydration is a simple process that facilitates the processing of fruits and vegetables, such as bananas, figs, pineapples, mangoes, apples, grapes, carrots, pumpkins, etc. with preservation of the initial characteristics of the fruit. Quince samples were treated with different osmotic solutions concentrations, 40, 60 and $80 \%$, to evaluate the effect of immersion time on moisture content and biochemical characteristics. Table 1 shows the moisture content data during osmotic dehydration versus quince sampling immersion time.

Physico-chemical parameters of fresh and osmotic dehydrated quince samples

Table 1

\begin{tabular}{|c|c|c|c|c|c|}
\hline Parameters & $\begin{array}{c}\mathbf{M} \\
\mathbf{\%}\end{array}$ & $\begin{array}{c}\text { Dry matter } \\
\mathbf{\%}\end{array}$ & $\mathbf{a}_{\mathbf{w}}$ & $\begin{array}{l}\mathbf{A A}^{\mathbf{a}} \\
\mathbf{m g} / \mathbf{1 0 0} \mathbf{g}\end{array}$ & $\begin{array}{c}\mathbf{T P}^{\mathbf{a}} \\
\mathbf{m g} \mathbf{G A E} / \mathbf{1 0 0 g}\end{array}$ \\
\hline Fresh quince & $83.8 \pm 0.554$ & $16.36 \pm 0.554$ & $0.63 \pm 0.11$ & $18.66 \pm 0.425$ & $80.3 \pm 0.929$ \\
\hline $\mathrm{FOD}_{40}$ & $76.6 \pm 0.79$ & $23.4 \pm 0.79$ & $0.56 \pm 0.15$ & $29.17 \pm 0.23$ & $81.47 \pm 0.40$ \\
\hline FOD $_{60}$ & $72.66 \pm 0.44$ & $27.09 \pm 0.44$ & $0.54 \pm 0.14$ & $29.36 \pm 0.49$ & $91.13 \pm 0.85$ \\
\hline $\mathrm{FOD}_{80}$ & $68.09 \pm 0.34$ & $31.91 \pm 0.49$ & $0.50 \pm 0.16$ & $30.9 \pm 0.26$ & $94.83 \pm 0.504$ \\
\hline SOD $_{40}$ & $78.9 \pm 0.19$ & $21.1 \pm 0.34$ & $0.56 \pm 0.12$ & $21.06 \pm 0.31$ & $84.9 \pm 0.58$ \\
\hline SOD $_{60}$ & $75.20 \pm 0.21$ & $25.79 \pm 0.48$ & $0.56 \pm 0.13$ & $21.43 \pm 0.27$ & $91.13 \pm 0.85$ \\
\hline SOD $_{80}$ & $71.92 \pm 0.38$ & $31.40 \pm 0.75$ & $0.52 \pm 0.11$ & $22.06 \pm 0.24$ & $97.06 \pm 0.81$ \\
\hline
\end{tabular}

${ }^{\mathrm{a}}$ Values are referred to $\mathrm{mg} / 100 \mathrm{~g}$ fresh weight vegetable;

Values (means $\pm \mathrm{SE})(n=3)$;

$\mathrm{M}=$ Moisture (g water/100 $\mathrm{g}$ of sample) \%;

$\mathrm{AA}=$ Ascorbic acid $\mathrm{mg} / 100 \mathrm{~g}$;

$\mathrm{TP}=$ content of Total Phenols (mg GAE/100 g);

$\mathrm{FOD}=$ Osmotic dehydration with fructose solution $40 \%$; $60 \%$ and $80 \%$;

SOD $=$ Osmotic dehydration with fructose solution $40 \%$; $60 \%$ and $80 \%$.

Time of osmotic dehydration had a significant effect on moisture content. Thus moisture content of fresh quince samples ranged from $83.8 \%$ in fresh quince to $68.09 \%$ in sample treated with $80 \%$ fructose solution. This decrease in moisture content is in agreement with previous research (Derossi et al., 2008). As can be seen, the use of the osmotic dehydration (OD) process resulted in an increase in the dry matter content.

Water is the environment for the development of chemical processes that take place in food during processing, but water also participates as reactant in hydrolytic processes. Food stability is a characteristic related to the variation of the water content in them. The value of water activity for fresh quince is high, which may explain the higher L*. A high-water content may cause an increase of the reflected light. The effect of osmotic dehydration on quince was achieved by varying the concentration of the sucrose solution $\left(40-60^{\circ} \mathrm{Brix}\right)$ and the immersion time (60-120 min). At a constant water activity, the decrease in the value for the equilibrium moisture content with the increase of air temperature was observed for quince (Noshad et al., 2012).

The total phenolic content recorded in fresh quince pulp was $80.3 \mathrm{mg} \mathrm{GAE} / 100 \mathrm{~g}$, it can be seen that osmotic dehydration treatments with $80 \%$ osmotic solution increase the content of total polyphenols ( $18.09 \%$ for fructose solution and $14.32 \%$ for sucrose solution).The 
results of the phenolic content obtained in this research are almost similar to the findings published by Rasheed et al. (2018), they reported a total phenolic content in quince fruit pulp from $65.73 \mathrm{mg} \mathrm{GAE} / 100 \mathrm{~g}$ to $68.13 \mathrm{mg} \mathrm{GAE} / 100 \mathrm{~g}$.

During the osmotic dehydration of quince fruit, some differences can be observed in the ascorbic acid content. The ascorbic acid content increased in a non-linear manner over time, at all concentrations of fructose and sucrose during osmotic dehydration of quince. The ascorbic acid values found in the present study agreed well with previously reported data. Studying the chemical characteristics of 22 quince genotypes and cultivars (Cydonia oblonga Mill.), the content of vitamin $\mathrm{C}$ was the highest in the Muškatová variety containing up to $79.31 \pm 2.01 \mathrm{~g} / 100 \mathrm{~g} \mathrm{FW}$ (Rop et al., 2011).

Riva et al. (Riva et al., 2005) studied the relationship between shrinkage and colour stability during osmodehydration and air dehydration, and chemical characteristics of apricot cubes. The ascorbic acid content increased with the pre-treatment time and was similar in the treatment with sorbitol, while the values were higher in the osmodehydration of sucrose (Riva et al., 2005).

\section{Effect of osmotic agent's types and its concentration on weight loss}

Results obtained by applying the statistical one-way analysis of variance (ANOVA) method showed that the moisture of quince samples after osmotic dehydration with fructose solution $80 \%$ had the lowest mean (Figure 1a), comparative with the fresh quince samples which had obvious, the highest mean regarding the moisture content. As shown in Figure 1b, the moisture of quince samples after osmotic dehydration, considering all three concentrations (40, 60 and $80 \%$ ) of fructose solution, cannot be grouped in the same category and the means are significantly different. Based on the value obtained for $\mathrm{R}^{2}(95.37 \%)$ it can be said that the model fits well with our data and the factor explains $95.37 \%$ of the variation of the response. It can be established that the differences between some of the means are statistically significant due to the $p$-value obtained $(0.000)$, in the case of quince samples moisture when the osmotic dehydration is performed with fructose solution.
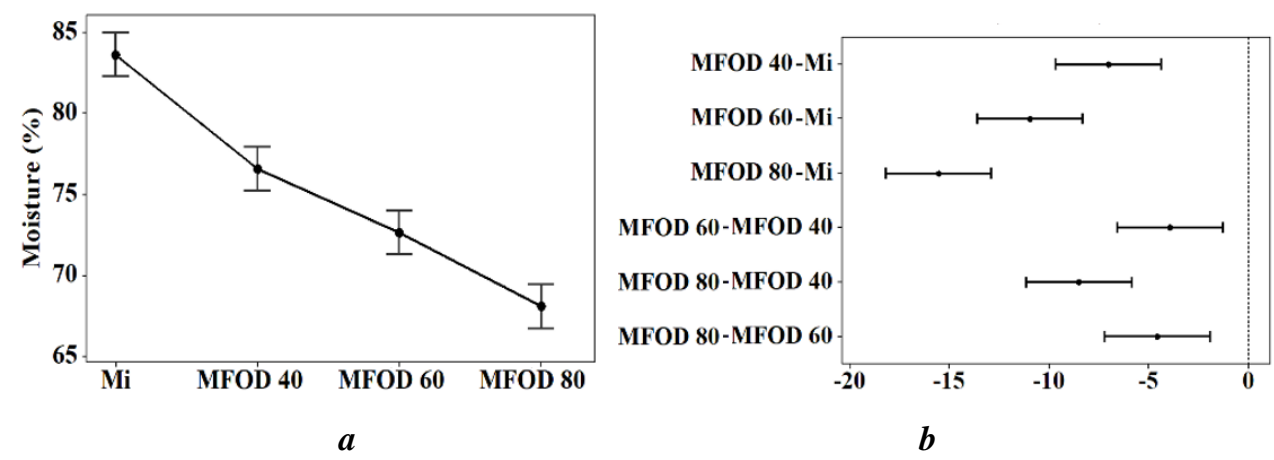

Figure 1.

$a$ - Interval plot for quince moisture (moisture of fresh quince samples - Mi, moisture after osmotic dehydration with fructose solution - MFOD (40\%, $60 \%$ and $80 \%)$ ); $b$ - comparison of data by using Tukey method 
As well, in the case of quince samples moisture after osmotic dehydration with sucrose solution, it was obtained $p=0.000$. These means that the differences between some of the means are statistically significant. Results illustrated in Figure $2 \mathrm{a}$ indicate that quince samples after osmotic dehydration with sucrose solution $80 \%$ has lowest mean, similar to osmotic dehydration with fructose solution. Moisture loss through dehydration of quince samples is higher when osmotic dehydration is performed with fructose solution compared to sucrose solution. In Figure $2 \mathrm{~b}$ it can be observed that the means are significantly different, since the intervals do not contain zero. The value obtained for $\mathrm{R}^{2}$ was $96.36 \%$, which means that the factor explains $96.36 \%$ of the variation in the response.
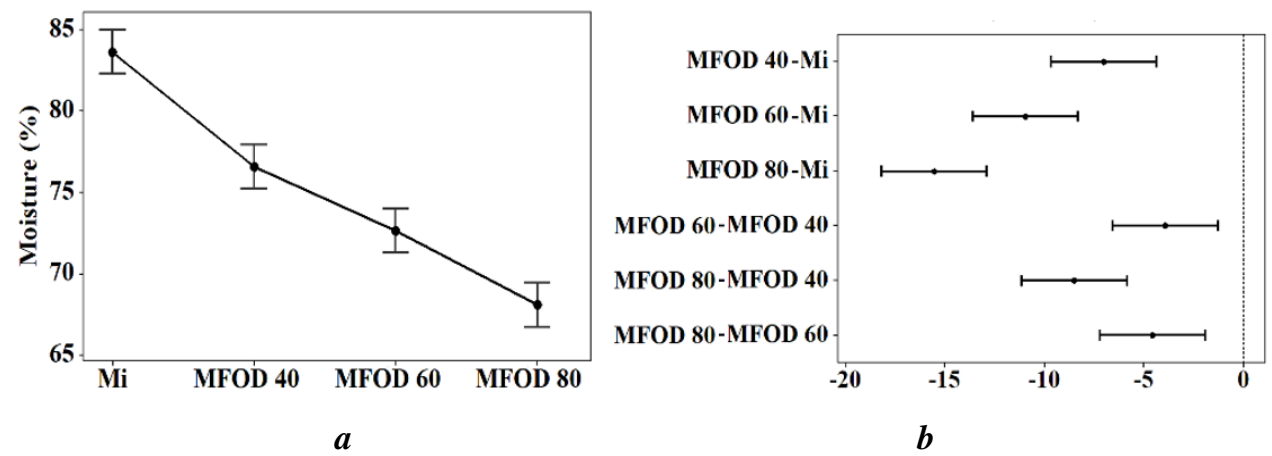

Figure 2.

$a$ - Interval plot for quince moisture (moisture of fresh quince samples - Mi, moisture after osmotic dehydration with fructose solution - MFOD (40\%, $60 \%$ and $80 \%)$ ); $b$ - comparison of data by using Tukey method

Weight reduction (WR, \%) of quince samples (10 mm), during the osmotic dehydration, increased in time according to the results presented in Figure 3. It can be observed that the higher values of WR were obtained when quince samples were dehydrated with fructose solution of $80 \%$ concentration (Figure 3a), and with sucrose solution of $80 \%$ concentration (Figure 3b). Results showed that weight reduction increases with increasing concentration of solutions, and this was also stated by (Leahu et al., 2020; Kayak-Ertekin et al., 2000). The WR values are also influenced by the quince slices size (Figure 4), it was determined that thinner slices $(10 \mathrm{~mm})$ have a higher WR value compared to thicker slices $(20 \mathrm{~mm})$ after 180 min of osmotic dehydration with fructose solution (40\%), otherwise WR had higher values for $20 \mathrm{~mm}$ slices.

The results showed that the values of weight loss of quince slices of $10 \mathrm{~mm}$, dehydrated in $40 \%$ sucrose solution are higher after $30 \mathrm{~min}, 120 \mathrm{~min}, 150 \mathrm{~min}$ and $180 \mathrm{~min}$ of dehydration, compared to the values obtained for $20 \mathrm{~mm}$ slices. Also, it can be seen that WR values are higher when the fructose solution is used (Figure 4). 


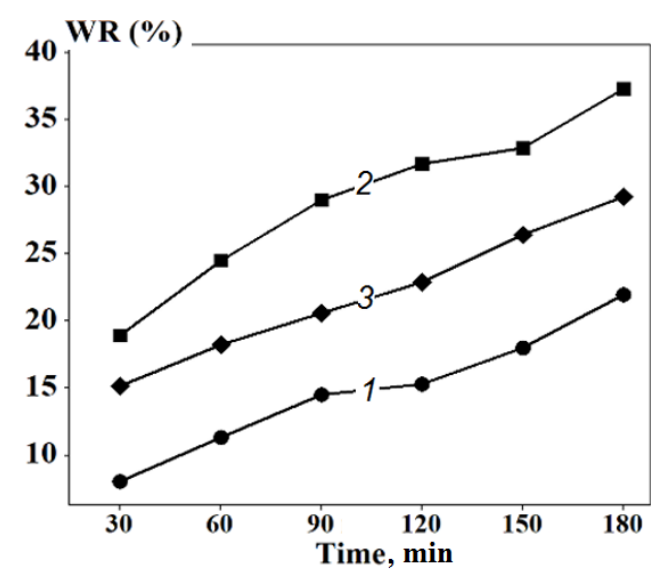

$\boldsymbol{a}$

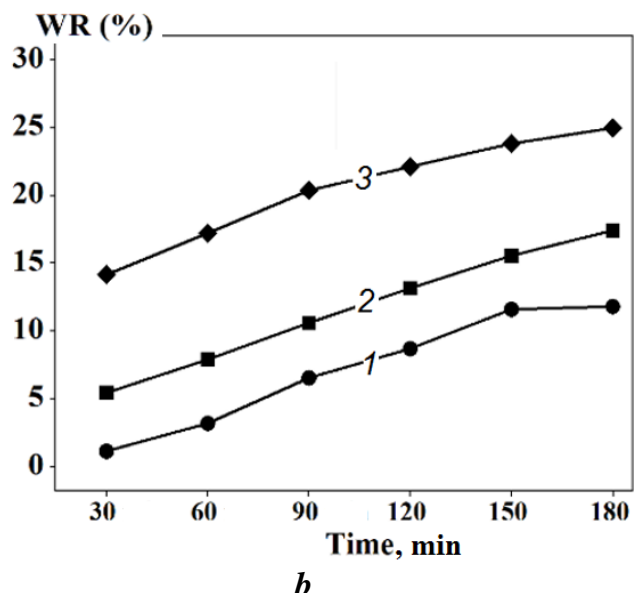

$b$

Figure 3. Variation of weight reduction (WR, \%) in time of quince samples $(10 \mathrm{~mm})$ during osmotic dehydration with different concentration of $a$-fructose solution; $b$ - sucrose solution:

Variable:

1 - WR_FS 40\%;

2-WR_FS 60\%;

2 - WR_FS 80\%.

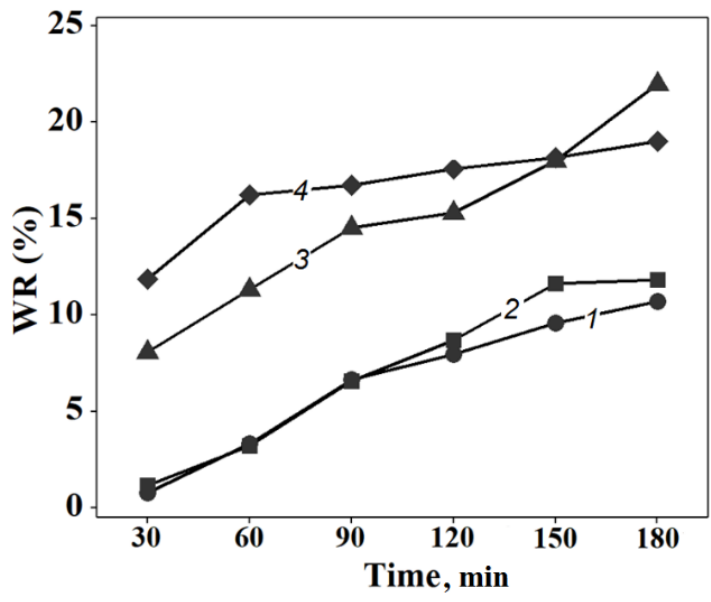

Figure 4. Variation of WR (\%) in time of quince samples $(10$ and $20 \mathrm{~mm})$ during osmotic dehydration with sucrose solution (SS) and fructose solution (FS),

both with a concentration of $40 \%$.

Variable:

1 - quince $(20 \mathrm{~mm})$ in SS

2 - quince $(10 \mathrm{~mm})$ in SS

3 - quince $(20 \mathrm{~mm})$ in FS

4 - quince $(10 \mathrm{~mm})$ in FS 
The $p$-values obtained were lower than $\alpha$-value, for both types of solution used for osmotic dehydration ( $p=0.002$ in case of WR obtained for dehydration of quince slices with fructose solution and $p=0.000$ when dehydration is done with sucrose solution) and these mean that the differences between some of the means are statistically significant. From Figures $5 \mathrm{a}$ and $5 \mathrm{c}$ it can be seen that the WR of quince samples after osmotic dehydration with fructose solution $80 \%$ and sucrose solution $80 \%$ have the highest mean. The WR of quince samples after osmotic dehydration with fructose solution (FS) $40 \%$ and $80 \%$ can be grouped in the same category, as well as WR FS 60\% and $80 \%$ (Figure 5b). In the case of osmotic dehydration with sucrose solution (SS), the WR of quince samples can be grouped in the same category only for WR SS $40 \%$ and $60 \%$ (Figure 5d). Their means are not significantly different, when they can be grouped in the same category. The factor explains $37.25 \%$ of the variation in the response $\left(\mathrm{R}^{2}=37.25 \%\right)$ in the case of samples dehydrated with fructose solution and $50.70 \%\left(\mathrm{R}^{2}=50.70 \%\right)$ for samples dehydrated with sucrose solution, respectively.
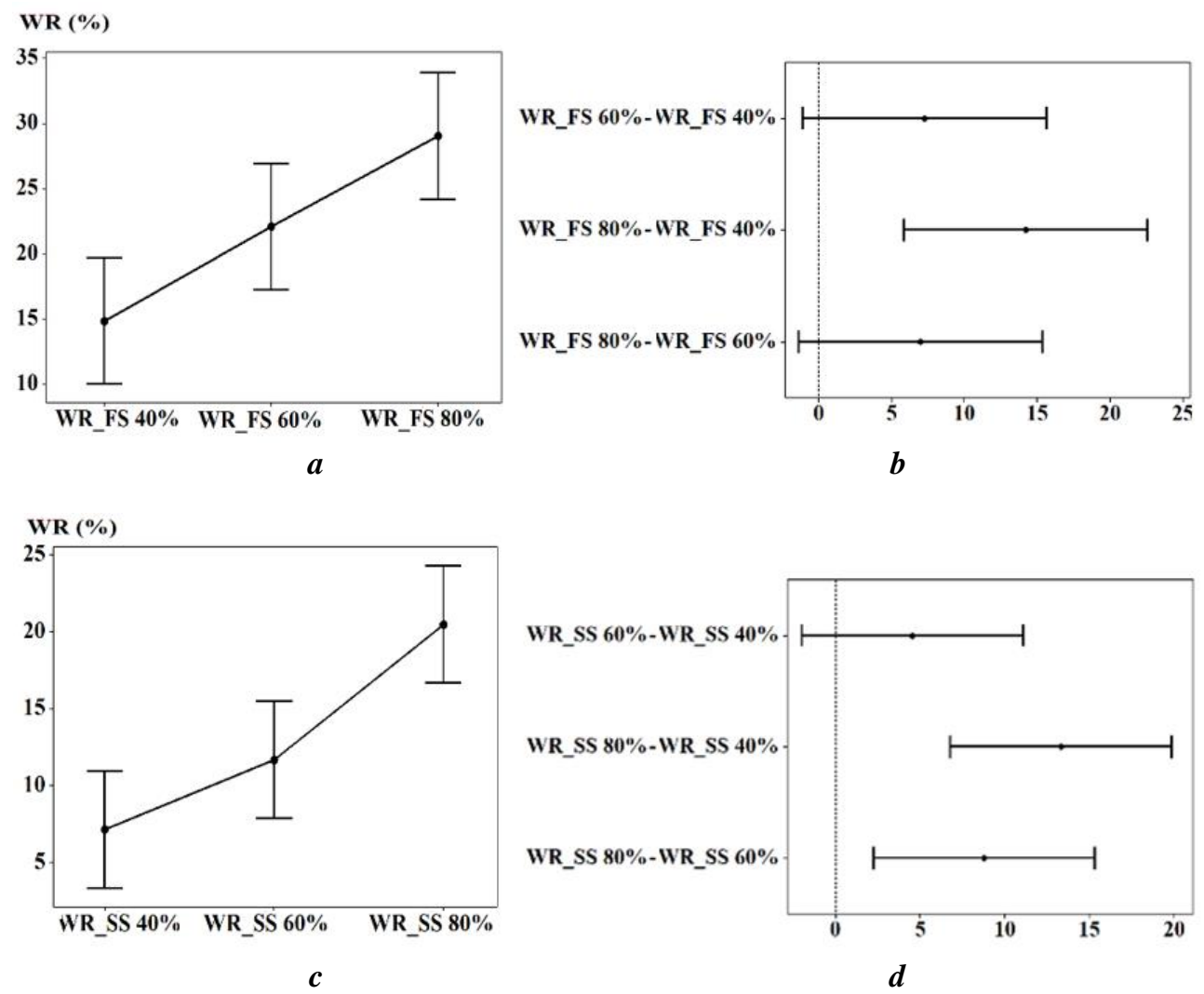

Figure 5. Interval plot for WR of quince samples $(10 \mathrm{~mm})(\mathrm{WR}(\%)$ after osmotic dehydration (OD) with: a - fructose solution (FS) and c-sucrose solution (SS);

WR comparison of data by using Tukey method b - OD with FS and d - OD with SS 


\section{CIE colour coordinates}

CIE $L^{*}, a^{*}$, and $b^{*}$ values of quince slices after osmotic dehydration using different osmotic solutions are presented in Table 2.

Colour CIELAB parameters for samples during the osmotic dehydration

Table 2

\begin{tabular}{|l|c|c|c|c|c|}
\hline Samples & $\mathbf{L}^{*}$ & $\mathbf{a}^{*}$ & $\mathbf{b}^{*}$ & Hue angle & Chroma \\
\hline Quince initial & 41.8 & 1 & 3.33 & 66.43 & 3.73 \\
\hline $\begin{array}{l}\text { Quince after treatment with } \\
\text { fructose 40\% solution }\end{array}$ & 36.06 & 4.53 & -1.26 & 33.93 & 4.76 \\
\hline $\begin{array}{l}\text { Quince after treatment with } \\
\text { fructose 60 \% solution }\end{array}$ & 33.73 & -1.8 & 1.26 & 28.05 & 4.13 \\
\hline $\begin{array}{l}\text { Quince after treatment with } \\
\text { fructose 80\% solution }\end{array}$ & 29.25 & -2.31 & 1.01 & 26.41 & 4.86 \\
\hline $\begin{array}{l}\text { Quince after treatmentwith } \\
\text { sucrose 40 \% solution }\end{array}$ & 35.73 & 4.1 & -1.76 & 33.06 & 4.53 \\
\hline $\begin{array}{l}\text { Quince after treatmentwith } \\
\text { sucrose 60 \% solution }\end{array}$ & 32.06 & -1.55 & 1.11 & 27.63 & 4.38 \\
\hline $\begin{array}{l}\text { Quince after treatmentwith } \\
\text { sucrose 80 \%solution }\end{array}$ & 28.18 & -2.12 & 0.90 & 25.73 & 4.95 \\
\hline
\end{tabular}

The use of different osmotic agents affected the $\mathrm{L}^{*}, \mathrm{a}^{*}$, and $\mathrm{b}^{*}$ values of the final product during the osmotic process. Thus, for fresh quince the values were $\mathrm{L}^{*}=41.8, \mathrm{a}^{*}=1.00, \mathrm{~b}^{*}=3.33$, and for OD fruits with fructose solution these values ranged as follows: L from 36.06 to 29.25 , a ${ }^{*}$ from 4.53 to -2.33 , and $b^{*}$ from -1.26 to 1.01 . It can be observed that coordinate $L^{*}$ presents the lowest values 28.18 after treatment with sucrose $80 \%$ solution indicating that quince dehydrated presented a darker colour compared to the fresh samples. Chauhan et al. (Chauhan et al., 2011) reported that the color changes of the fruits (darkening) due to the enzymatic browning are correlated with the $\mathrm{L}^{*}$ and $\mathrm{a}^{*}$ values. Changes in the * (green - red) coordinate for dehydrated samples with sugar solution show a change in color from greenish yellow to fresh samples (1) in reddish yellow (-2.12).

The results of the current study were quite in agreement with those of El-Aouar et al. (El-Aoua et al., 2006); these authors reported that the concentration of the osmotic solution was the most important effect on weight loss of osmotically dehydrated slices of papaya (Carica papaya L.) with sucrose and corn syrup (El-Aoua et al., 2006).

\section{Conclusion}

1. Processing of quince by osmotic dehydration using three concentrations of fructose and sucrose solution $(40 \%, 60 \%$ and $80 \%)$ osmotic solutions significantly increased the total phenolic and acid ascorbic content in comparison to control sample.

2. Weight reduction (WR) were higher for fructose osmosis samples compared to sucrose osmosis samples at the same concentration of the solution. Both weight reduction (WR) increased with increasing osmotic agent concentration. This can be attributed to the fact 
that fructose is a low molecular weight monosaccharide and therefore has a more pronounced effect on water loss compared to sucrose which is a polysaccharide.

3. The studied factors of osmotic dehydration (process duration, type of agent and sugar solution concentration) showed a significant influence on weight reduction.

\section{References}

Ahmed I., Qazi I.M., Jamal S. (2016), Developments in osmotic dehydration technique for the preservation of fruits and vegetables, Innovative Food Science \& Emerging Technologies, 34, pp. 29-43.

Blanda G., Rodriguez-Roque M.J., Comandini P., Flores-Cordova M.A., Salas-Salazar N.A., Oscar C.A., Soto-Caballero M.C. (2020), Phenolic profile and physicochemical characterization of quince (Cydonia oblonga Mill) fruits at different maturity index, NotulaeBotanicaeHortiAgrobotanici Cluj-Napoca, 48(4), pp. 2306-2315.

Borazan A.A., Acikgoz C. (2017), Effect of quince variety on the quality of pectin: chemical composition and characterization, International Journal of Pharmaceutical, Chemical \& Biological Sciences, 7(4), pp. 393-400.

Chauhan O.P., Singh A., Singh A., Raju P.S., Bawa A.S. (2011), Effects of osmotic agents on colour, textural, structural, thermal, and sensory properties of apple slices, International Journal of Food Properties, 14(5), pp.1037-1048.

da Silva W.P., do Amaral D.S., Duarte M.E.M., Mata M.E., Silva C.M., Pinheiro R.M., Pessoa T. (2013), Description of the osmotic dehydration and convective drying of coconut (Cocos nucifera L.) pieces: a three-dimensional approach, Journal of Food Engineering, 115(1), pp. 121-131.

Dehghannya J., Hosseinlar S.H., Heshmati M.K. (2018), Multi-stage continuous and intermittent microwave drying of quince fruit coupled with osmotic dehydration and low temperature hot air drying, Innovative Food Science \& Emerging Technologies, 45, pp. 132-151.

Derossi A., De Pilli T., Severini C., McCarthy M.J. (2008), Mass transfer during osmotic dehydration of apples, Journal of Food Engineering, 86(4), pp. 519-528.

El-Aoua Â.A., Azoubel P.M., Barbosa Jr. J.L., Murr F.E.X. (2006), Influence of the osmotic agent on the osmotic dehydration of papaya (Carica papaya L.), Journal of Food Engineering, 75(2), pp. 267-274.

Fernandes F.A., Gallão M. I., Rodrigues S. (2009), Effect of osmosis and ultrasound on pineapple cell tissue structure during dehydration, Journal of Food Engineering, 90(2), pp. 186190.

İspir A., Toğrul İ.T. (2009), Osmotic dehydration of apricot: Kinetics and the effect of process parameters, Chemical Engineering Research and Design, 87(2), pp. 166-180.

Kaymak-Ertekin F., Sultanoğlu M. (2000), Modelling of mass transfer during osmotic dehydration of apples, Journal of Food Engineering, 46, pp. 243-250.

Leahu A., Ghinea C., Oroian M.A. (2020), Osmotic dehydration of apple and pear slices: color and chemical characteristics, Ovidius University Annals of Chemistry, 31(2), pp. 73-79.

Leahu A., Ghinea C., Oroian M.A., Damian C. (2018), Determination of essential and toxic elements, ascorbic acid content and color of different leaves in two cabbage varieties, Ovidius University Annals of Chemistry, 29(2), pp. 110-116.

Leahu A., Ghinea C., Ropciuc S., Oroian M.A., Damian C. (2019), Polyphenol-rich smoothies: sensory and chemical characterization, Studia Universitatis Vasile Goldis Seria Stiintele Vietii (Life Sciences Series), 29, pp. 37-45.

Mandala I. G., Anagnostaras E.F., Oikonomou C.K. (2005), Influence of osmotic dehydration conditions on apple air-drying kinetics and their quality characteristics, Journal of Food Engineering, 69(3), pp. 307-316. 


\section{- Food Technology}

McEvily A.J., Iyengar R., Otwell W.S. (1992), Inhibition of enzymatic browning in foods and beverages, Critical Reviews in Food Science \& Nutrition, 32(3), pp. 253-273.

Noshad M., Mohebbi M., Shahidi F., Mortazavi S.A., (2012), Effect of osmosis and ultrasound pretreatment on the moisture adsorption isotherms of quince, Food and Bioproducts Processing, 90(2), pp. 266-274.

Prothon F., AhrnéL.M., Funebo T., Kidman S., Langton M., Sjöholm I. (2001), Effects of combined osmotic and microwave dehydration of apple on texture, microstructure and rehydration characteristics, LWT-Food Science and Technology, 34(2), pp. 95-101.

Qin Z., Liu H.M., Lv T.T., Wang X.D. (2020), Structure, rheological, thermal and antioxidant properties of cell wall polysaccharides from Chinese quince fruits, International Journal of Biological Macromolecules, 147, pp. 1146-1155.

Rasheed M., Hussain I., Rafiq S., Hayat I., Qayyum A., Ishaq S., Awan M.S. (2018), Chemical composition and antioxidant activity of quince fruit pulp collected from different locations, International Journal of Food Properties, 21(1), pp. 2320-2327.

Riva M., Campolongo S., Leva A.A., Maestrelli A., Torreggiani D. (2005), Structureproperty relationships in osmo-air-dehydrated apricot cubes, Food Research International, 38(5), pp. 533-542.

Rop O., Balik J., Řezníček V., Juríková T., Škardová P., Salaš P., Sochor J., Mlček J., Kramáŕová D. (2011), Chemical characteristics of fruits of some selected quince (Cydonia oblonga Mill.) cultivars, Czech Journal of Food Sciences, 29 (1), pp. 65-73.

Silva B.M., Andrade P.B., Valentão P., Ferreres F., Seabra R.M., Ferreira M.A. (2004), Quince (Cydonia oblonga Miller) fruit (pulp. peel. and seed) and jam: antioxidant activity, Journal of Agricultural and Food Chemistry, 52(15), pp. 4705-4712.

Stankov S., Fidan H., Petkova N., Stoyanova A., Dincheva I., Dogan H., Şenkal B.G., Uskutoğlu T., Bas H., Yilmaz G. (2020), Phytochemical composition of Helichrysumarenarium (L.) Moench essential oil (aerial parts) from Turkey, Ukrainian Food Journal, 9(3), pp 503-512.

Turkiewicz I.P., Wojdyło A., Lech K., Tkacz K., Nowicka P. (2019), Influence of different drying methods on the quality of Japanese quince fruit, $L W T, 114,108416$.

Turkiewicz I.P., Wojdyło A., Tkacz K., Lech K., Nowicka P. (2020), Osmotic Dehydration as a Pretreatment Modulating the Physicochemical and Biological Properties of the Japanese Quince Fruit Dried by the Convective and Vacuum-Microwave Method, Food and Bioprocess Technology, 13(10), pp. 1801-1816.

Wojdyło A., Teleszko M., Oszmiański J. (2014), Antioxidant property and storage stability of quince juice phenolic compounds, Food chemistry, 152, pp. 261-270.

Yadav A.K., Singh S.V. (2014), Osmotic dehydration of fruits and vegetables: a review, Journal of Food Science and Technology, 51(9), pp. 1654-1673.

Zielinska M., Michalska A. (2016), Microwave-assisted drying of blueberry (Vaccinium corymbosum L.) fruits: Drying kinetics, polyphenols, anthocyanins, antioxidant capacity, colour and texture, Food Chemistry, 212, pp. 671-680. 